\title{
Circulating species of Leishmania at microclimate area of Boulemane Province, Morocco: impact of environmental and human factors
}

Asmae Hmamouch ${ }^{1,2^{*}}$, Mahmoud Mohamed El Alem ${ }^{1,3}$, Maryam Hakkour ${ }^{1,3}$, Fatima Amarir ${ }^{4}$, Hassan Daghbach ${ }^{5}$, Khalid Habbari ${ }^{6}$, Hajiba Fellah ${ }^{1,3}$, Khadija Bekhti ${ }^{2}$ and Faiza Sebti ${ }^{1,6}$

\begin{abstract}
Background: Cutaneous leishmaniasis $(\mathrm{CL})$ is widely distributed in Morocco where its geographical range and incidence are related to environmental factors. This study aimed to examine the impact of several factors on the distribution of $\mathrm{CL}$ in Boulemane Province, which is characterized by several microclimates, and to identify the Leishmania species circulating in these areas.

Methods: Ordinary least squares regression (OLSR) analysis was performed to study the impact of poverty, vulnerability, population density, urbanization and bioclimatic factors on the distribution of $\mathrm{CL}$ in this province. Molecular characterization of parasites was performed using a previously described PCR-RFLP method targeting the ITS1 of ribosomal DNA of Leishmania.

Results: A total of 1009 cases were declared in Boulemane Province between the years 2000 and 2015 with incidences fluctuating over the years $(P=0.007)$. Analyzing geographical maps of the study region identified four unique microclimate areas; sub-humid, semi-arid, arid and Saharan. The geographical distribution and molecular identification of species shows that the Saharan microclimate, characterized by the presence of Leishmania major was the most affected (47.78\%) followed by semi-arid area where Leishmania tropica was identified in three districts. Among several environmental factors included in the study, poverty had the greatest influence on the spatial extension of the disease in this province.

Conclusions: The incidence of $\mathrm{CL}$ in Boulemane Province varies between microclimate areas, and environmental factors partly explain this variation. However, the existence of $\mathrm{CL}$ in the most affected districts is mainly related to poverty, population movement and human behavior. To our knowledge, this the first study utilizing molecular techniques to confirm L. tropica and L. major as the causative agents of $C L$ in Boulemane Province. Our findings indicate that the spatial and temporal distribution of $\mathrm{CL}$ in Boulemane Province is strongly related to poverty and population movement.
\end{abstract}

Keywords: Leishmania tropica, Leishmania major, Environmental factors, OLSR, Boulemane, Morocco

\footnotetext{
* Correspondence: asmae.hmamouch@gmail.com

${ }^{1}$ National Reference Laboratory of Leishmaniasis, National Institute of

Hygiene, Rabat, Morocco

${ }^{2}$ Laboratory of Microbial Biotechnology, Sciences and Techniques Faculty,

Sidi Mohammed Ben Abdellah University, Fez, Morocco

Full list of author information is available at the end of the article
} 


\section{Background}

Leishmaniasis is among the most important emerging vector-borne protozoal diseases in terms of disability adjusted life year (DALY's). Approximately, 1.5 million cases of cutaneous leishmaniasis (CL) and 500,000 cases of visceral leishmaniasis (VL) are reported each year and approximately 350 million people are at risk [1]. Leishmaniasis is caused by any of several parasites belonging to the genus Leishmania (Kinetoplastida: Trypanosomatidae), that are transmitted via the bite of phlebotomine sand flies (Diptera: Psychodidae). The disease is represented by three main clinical syndromes: mucocutaneous, visceral and $\mathrm{cu}-$ taneous leishmaniasis, the latter two being the most common [1]. In Morocco, 2933 cases of CL were declared in 2015 with fluctuations in the number of cases reported over the years [2]. As with other vector-borne diseases, the geographical distribution of cases suggests that CL transmission is sensitive to vector density which is correlated to climatic conditions [3]. Due to its geographical position, Morocco possesses different ecological and climatic conditions [4] which influence the distribution and epidemiology of endemic disease such as leishmaniasis. Based on the bioclimatic map of Morocco, the distribution of sand flies revealed a diversity of species with specific rain-thermal preferences [5].

The objectives of this study are to (i) determine the impact of these environmental conditions on the distribution of $\mathrm{CL}$ in this province, (ii) identify the roles of the socio-economic factors on the distribution of $\mathrm{CL}$, and (iii) identify the Leishmania species responsible for $\mathrm{CL}$ in this province using molecular techniques.

\section{Methods}

\section{Study area}

Boulemane Province $\left(33^{\circ} 3^{\prime}-33^{\circ} 0^{\prime} \mathrm{N}, 3^{\circ} 59^{\prime}-3^{\circ} 27^{\prime} \mathrm{W}\right)$ belongs to the region of Fes-Boulemane in central Morocco. This province extends over a large surface of $14,395 \mathrm{~km}^{2}$ (71\% of the region). Administratively, this province is composed of 21 districts (four urban and 17 rural) and is bordered to the north by Sefrou and Taza provinces, to the west by Ifrane Province, to the south by Khenifra, Errachidia and Figuig provinces and to the east by Taourirt Province [6]. Climatically, Boulemane Province contains four bioclimates: (i) a subhumid bioclimate with moderate winters and precipitation varying from 700 to $800 \mathrm{~mm}$ with a mean temperature of $13.9^{\circ}$ C; (ii) a semi-arid bioclimate characterized by a cold winter (rainfall is about $450 \mathrm{~mm}$ per year and mean temperature of $15.6{ }^{\circ} \mathrm{C}$ ) and hot summers; (iii) an arid bioclimate with very cold winters (rainfall is about $130 \mathrm{~mm}$ per year and an average temperature of $16.7^{\circ}$ C); and (iv) a Saharan bioclimate with rainfall of approximately $74 \mathrm{~mm}$ per year and a mean temperature of $17.6{ }^{\circ} \mathrm{C}$ [7]. Geographically, this province is divided into two areas: a mountainous area that includes the mountain of Tichoukt with a maximum elevation of 2,796 m, and is crossed by the major rivers of M'daz, Guigou and Maasar and a pre-Saharan area that includes plains, valleys and the high plateaus of Moulouya where there is irrigated agricultural land. Olives and fruit are the main agricultural commodities and are of significant economic importance to this province. Boulemane Province is famous for its deposits of ghassoul located near Ksabi District, which extends over 25,000 ha [6]. This province had a total of 197,596 inhabitants in 2014 [8].

\section{Epidemiological data and statistical analyses}

The epidemiological study was performed using 1009 cases of CL reported between 2000 and 2015, clinically diagnosed in the health center of Boulemane Province. Data related to human cases of leishmaniasis were provided by the Directorate of Epidemiology and Disease Control [2]. Data on the poverty rate, vulnerability rate, population density and the two degrees of urbanization (rural/urban) were established for each district of Boulemane Province. These data were obtained from the High Commission for Planning [9]. Data concerning the bioclimatic areas in this province were provided by the agency of Sebou Hydraulic basin and from the Ministry of Housing and Urban Planning in Morocco [10].

Statistical analysis was performed using the IBM SPSS Statistical software version 24.0. The ordinary least squares regression model was applied to assess the impact of several factors: poverty rate, vulnerability rate, population density, urbanization and bioclimatic area on the distribution of leishmaniasis in Boulemane Province. For all statistical methods, a cut-off of $P=0.05$ was used.

\section{Molecular methods}

In outbreaks of leishmaniasis, the consultants of the World Health Organization recommend that health professionals make a clinical diagnosis and microscopically confirm the first cases of leishmaniasis declared in suspected outbreak. It is recommended that later cases receive treatment based on a clinical diagnosis in the absence of a microscopic diagnosis [11]. Consequently, our laboratory received stained slides for approximately $47 \%$ of leishmaniasis cases declared (59 cases) during 2015 in Boulemane Province ( 28 slides in total). These slides were subjected to DNA extraction using a Qiagen DNA minikit, according to the manufacturer's instructions (Qiagen, Hilden, Germany) [12]. The internal transcribed spacer (ITS1) region was amplified using primers LITSR: 5' -TGATACCACTTATCGCACTT-3' and L5.8S: 5'-CTGGATCATTTTCCGATG-3' [13]. Amplification of the target genes was carried out in a total volume of $25 \mu \mathrm{l}$ containing $20 \mathrm{pmol} / \mu \mathrm{l}$ of each primer (Eurofins MWG Operon Anzingerstrabe 7a D-85560, Ebersberg, Germany), 5 unit/ $\mu$ l of Taqpolymerase (Promega, Adison, 
USA), $10 \mathrm{Mm}$ of each DNTPs and $25 \mathrm{mM}$ of $\mathrm{MgCl}_{2}$, and5 $\mu \mathrm{l}$ of DNA. The cycling program was initiated with an initial denaturation of $5 \mathrm{~min}$ at $95^{\circ} \mathrm{C}$, followed by 32 cycles of $94{ }^{\circ} \mathrm{C}$ for $30 \mathrm{~s}, 60^{\circ} \mathrm{C}$ for $45 \mathrm{~s}, 72{ }^{\circ} \mathrm{C}$ for $60 \mathrm{~s}$, then a final extension step at $72{ }^{\circ} \mathrm{C}$ for $5 \mathrm{~min}$. The ITS1amplicon was subjected to restriction fragment length polymorphism (RFLP) analysis using the endonuclease HaeIII as previously described [13]. Reference strains of Leishmania infantum (MHOM/MA/1998/LVTA),Leishmania tropica (MHOM/ MA/2010/LCTIOK-4) and Leishmania major (MHOM/ MA/2009/LCER19-09) were included in all analyses for comparison.

\section{Results}

Epidemiology of leishmaniasis in Boulemane Province Temporal distribution of CL cases in Boulemane Province from 2000 to 2015

In Boulemane Province the incidence of $\mathrm{CL}$ was low between the years 2000 and 2004 with an average six cases/ 100,000 inhabitants. In 2005, an increase of cases was observed with 59.75 cases/100,000 inhabitants. Thereafter, the incidence of leishmaniasis decreased to 25.67 cases/100,000 inhabitants in 2008. An increase in cases was noted in 2009 with 63.65 cases/100,000 inhabitants followed by a decrease in the last 2 years of the study (Fig. 1). The variation of cases between the years was significant according to the OLSR analysis $(P$-value $=0.007)($ Table 1$)$.

\section{Geographical distribution of leishmaniasis in Boulemane Province from 2000 to 2015}

In Boulemane Province CL was reported in each of the four bioclimatic areas between 2000 and 2015 (Fig. 2). The Saharan microclimate was the most affected with $47.78 \%$ (432 cases) of all cases reported, 53\% occurring in the rural district of Ksabi Moulouya. In the semi-arid area, 358 cases of CL (39.6\%) were distributed in 11 districts with more than half of all cases (55\%) in Skoura districts. In arid areas, 114 cases $(12.61 \%)$ were spread over six districts. The OLSR analysis (Table 1) revealed that the local microclimate has little effect on the number of cases of CL in this province.

Over the years, the spatial distribution of leishmaniasis (Fig. 3) showed that the disease was detected in 19 of the 21 districts in this province between the years 2000 and 2015. Between 2000 and 2004, the disease was limited to ten districts with an average of 4-5 cases/year. From 2005 to 2012 the disease was detected in 18 districts, though with most cases occurring in the districts of Ksabi, Skoura and Missour. By 2014, the incidence of leishmaniasis was relatively low in most district sexcept for Skoura district. The incidence of CL in Fritissa district was considered epidemic in 2015.

\section{Impact of environmental factors on the distribution of leishmaniasis in Boulemane Province}

OLSR showed that poverty had a significant effect on the incidence of leishmaniasis (Fig. 4, Table 1). However, the distribution of leishmaniasis in Boulemane Province was not correlated to population density (Fig. 5, Table 1), nor was it affected by the vulnerability rate (Fig. 6, Table 1) or urbanization (Table 1).

\section{Distribution of CL in Boulemane Province according to age, sex and clinical features}

The average age of Leishmania infected individuals was 21 years with a minimum of 6 months and a maximum of 95 years old (Fig. 7). The age group most represented was that of 0-9 years old with 362 cases. The age group of 10-19 years was in the second position with 238 cases. The age group 20-49 years was affected with an average of 69 cases. In this province 101 patients were older than 50 year-old. The distribution of cases by sex was uniform with $51 \%$ female and $49 \%$ are male. The number of lesions ranged from 1 to 5 lesions (Fig. 8). Most patients had two lesions (37.8\%), followed by single lesions (30\%). Multiple lesions were observed in $29 \%$ of

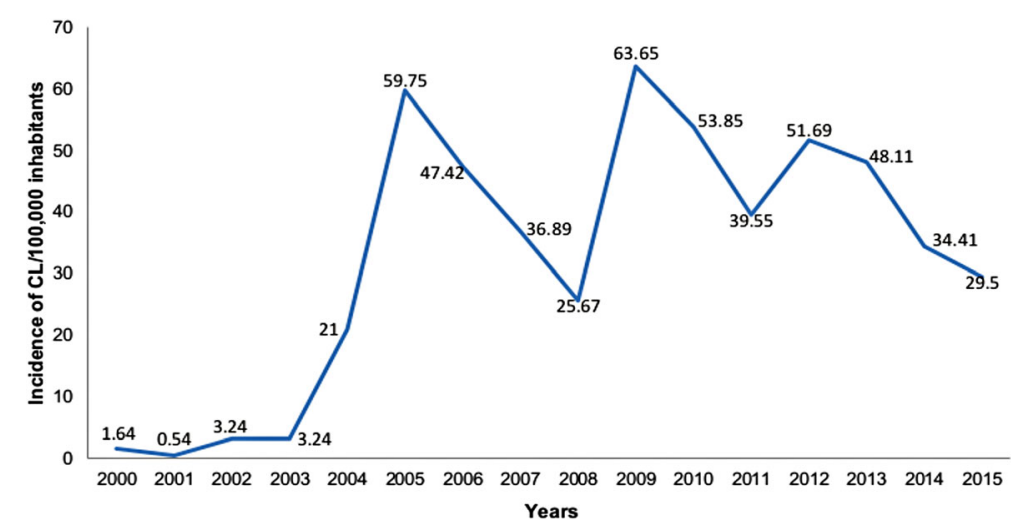

Fig. 1 Incidence rate of CL/100,000 inhabitants in Boulemane Province between 2000 and 2015 
Table 1 OLSRof human leishmaniasis cases, and environmental factors in Boulemane Province

\begin{tabular}{|c|c|c|c|c|}
\hline Factor & Variable & Coefficient & t-statistic & $P$-value \\
\hline \multirow[t]{3}{*}{ Year } & Intercept & $-11,370.830$ & -3.175 & 0.007 \\
\hline & Year & 5.696 & 3.192 & 0.007 \\
\hline & & Adjusted $R^{2}=0.380$ & $F_{(1,14)}=10.194$ & $F_{(1,14)}=0.007$ \\
\hline \multirow[t]{3}{*}{ Microclimate area } & Intercept & $3,640.333$ & 3.530 & 0.176 \\
\hline & Microclimate area & -159.000 & -3.240 & 0.191 \\
\hline & & Adjusted $R^{2}=0.826$ & $F_{(1,1)}=10.497$ & $F_{(1,1)}=0.191$ \\
\hline \multirow[t]{3}{*}{ Poverty } & Intercept & -631.73 & -0.47 & 0.654 \\
\hline & Poverty rate & 199.99 & 2.28 & 0.04 \\
\hline & & Adjusted $R^{2}=0.23$ & $F_{(1,13)}=5.19$ & $F_{(1,13)}=0.04$ \\
\hline \multirow[t]{4}{*}{ Density of population according to districts } & Intercept & 60.438 & 1.519 & 0.157 \\
\hline & Districts & -4.380 & -1.403 & 0.188 \\
\hline & Population & 0.000 & -0.298 & 0.772 \\
\hline & & Adjusted $R^{2}=0.238$ & $F_{(2,11)}=3.028$ & $F_{(2,11)}=0.090$ \\
\hline \multirow[t]{4}{*}{ Urbanization and vulnerability } & Intercept & 234.167 & 2.057 & 0.055 \\
\hline & Urbanization & 25.221 & 0.545 & 0.593 \\
\hline & Vulnerability rate & -9.344 & -1.855 & 0.081 \\
\hline & & Adjusted $R^{2}=0.30$ & $F_{(2,18)}=1.205$ & $F_{(2,18)}=0.338$ \\
\hline
\end{tabular}

patients. Most of lesions were observed on the face (44\%), followed by the upper limbs (30.6\%). In the lower limbs $25.4 \%$ of lesions were located (Fig. 9). The face and cheeks were the most frequent site of exposure (42\%) followed by the forehead with $14.5 \%$, and nose with $13 \%$. Other lesions mentioned on the face were on the chin, ears, eyes and lips. On the upper limbs, the hands were most commonly affected with $41 \%$ followed by the arm and forearm with $29.5 \%$ each. Finally, the legs were the preferred bite site of sandflies $(60 \%)$ on the lower limbs. The clinical aspect of lesions was examined in 342 patients (Fig. 10) where

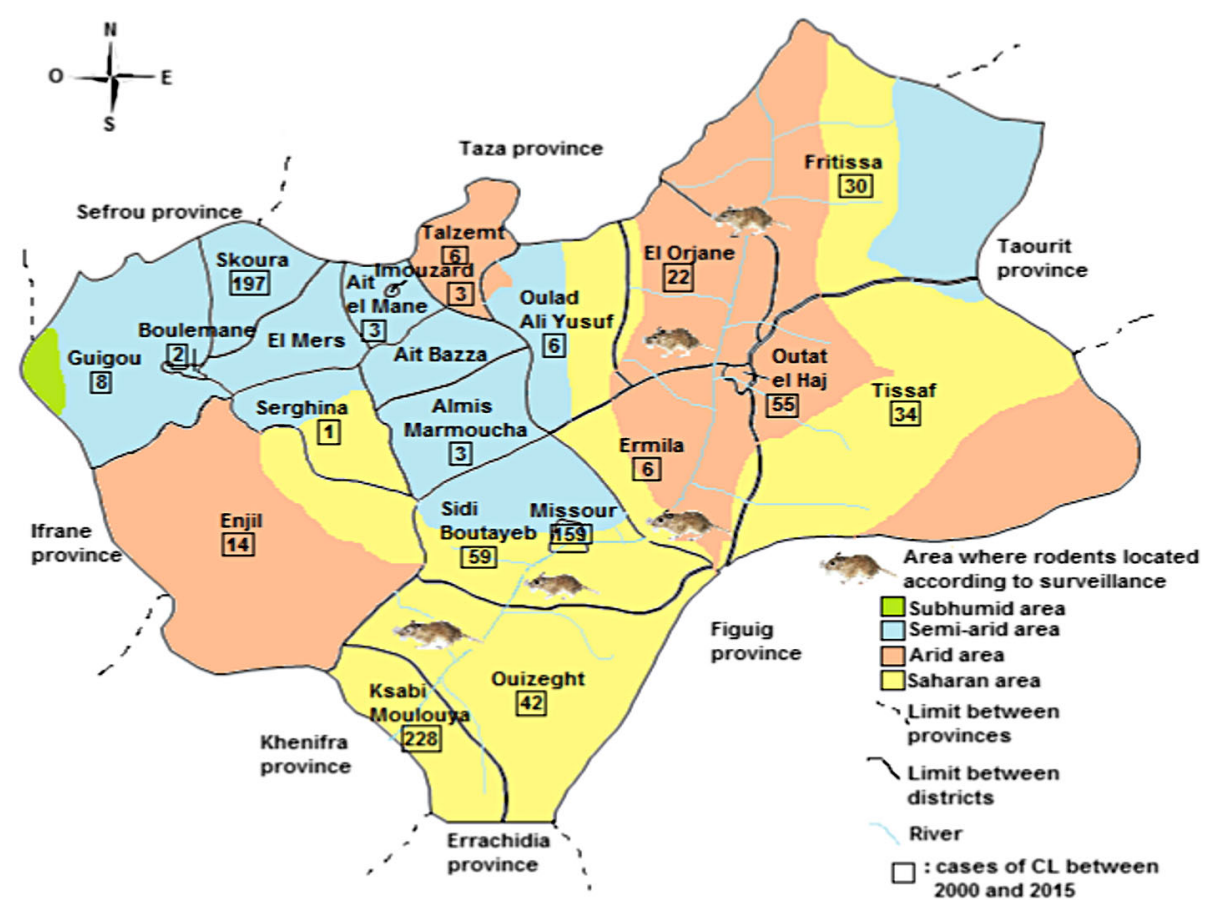

Fig. 2 Distribution of $C L$ according to microclimate area from 2000 to 2015 in Boulemane Province 

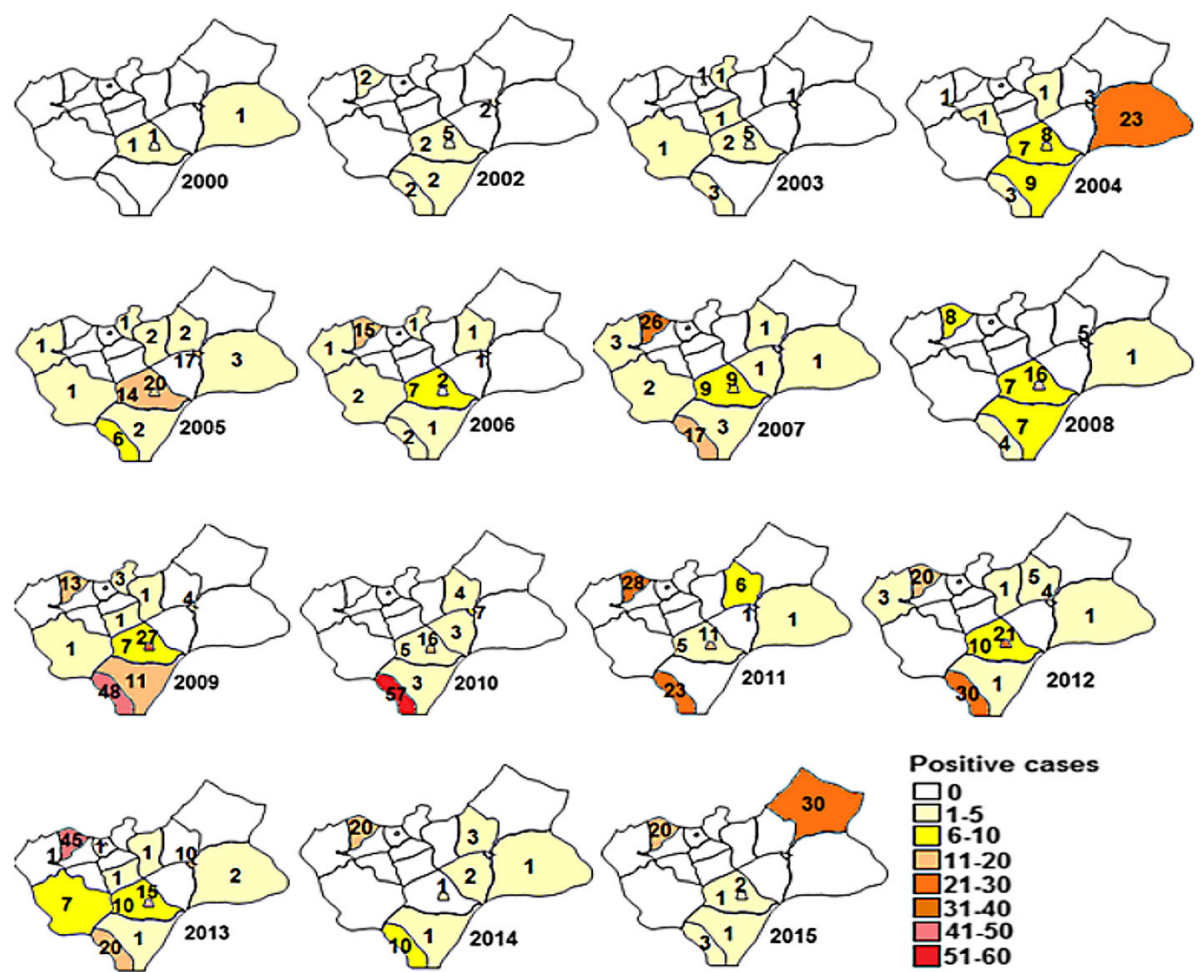

Fig. 3 Geographical distribution of CL cases in Boulemane Province, between 2000 and 2015

six aspects were identified. Ulcerative and crusted lesions predominated with 24 and $20 \%$, respectively. The scaly lesions were observed in 55 cases (16\%) followed by hollow, vegetative and lupoid lesions with an average of $13 \%$.

\section{Molecular study}

Of the 59 cases of CL declared in 2015, 28 were analyzed microscopically and were positive. All of them were positive after ITS1PCR-RFLP. Leishmania major was identified in five samples belonging to three different

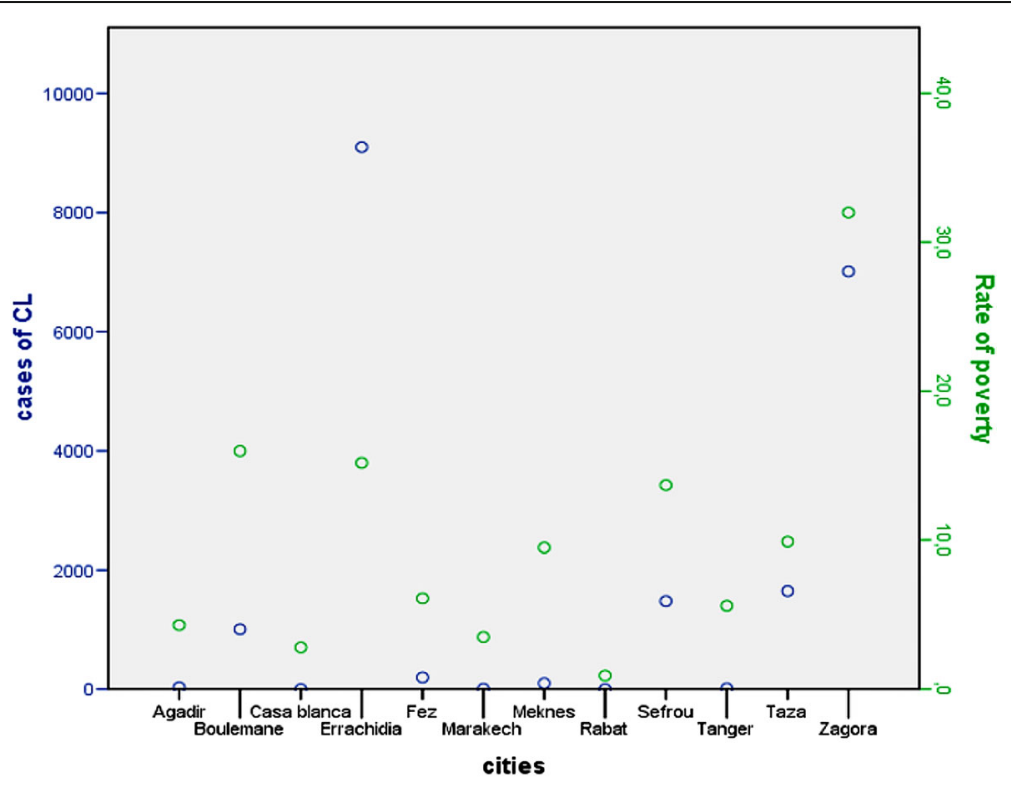

Fig. 4 Plot of distribution of leishmaniasis according to rate of poverty in Morocco 


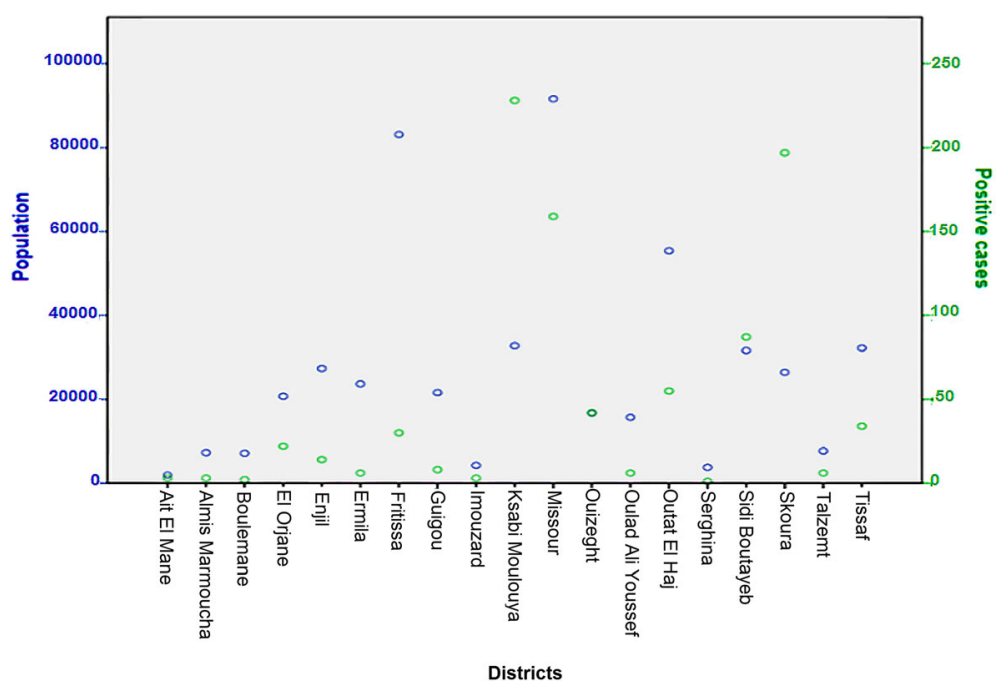

Fig. 5 Plot of distribution of $C L$ according to population in Boulemane Province

districts (Ksabi Moulouya, Sidi Boutayeb and Ouizeght) situated in the Saharan microclimate area. Concerning L.tropica, it was identified in three other districts (Missour, Fritissa and Skoura) owing to their Saharan and semi-arid microclimates (Table 2, Fig. 11).

\section{Discussion}

Leishmaniasis is a dynamic disease and the circumstances of transmission are continually changing in relation to environmental, demographic, socio-economic and human behavioral factors [14]. The only study performed in Boulemane Province identified L. tropica in seven samples without specifying their origin [15]. Our study aimed to determine the impact of several factors on the distribution of leishmaniasis by molecular epidemiological methods to identify the circulating species according to microclimate area affected in 2015. The results of our study suggest that the microclimate does not affect the number of cases of leishmaniasis (Table 2). However, the microclimate does appear to affect the distribution of Leishmania species [5]. Leishmania tropica was identified in Skoura, Missour and Fritissa. In the first district, this result could be explained by its semi-arid microclimate and its mountainous areas in which Phlebotomus sergent $i$ was the most commonly collected sandfly species in a previous report (60.4\%) followed by Phlebotomus

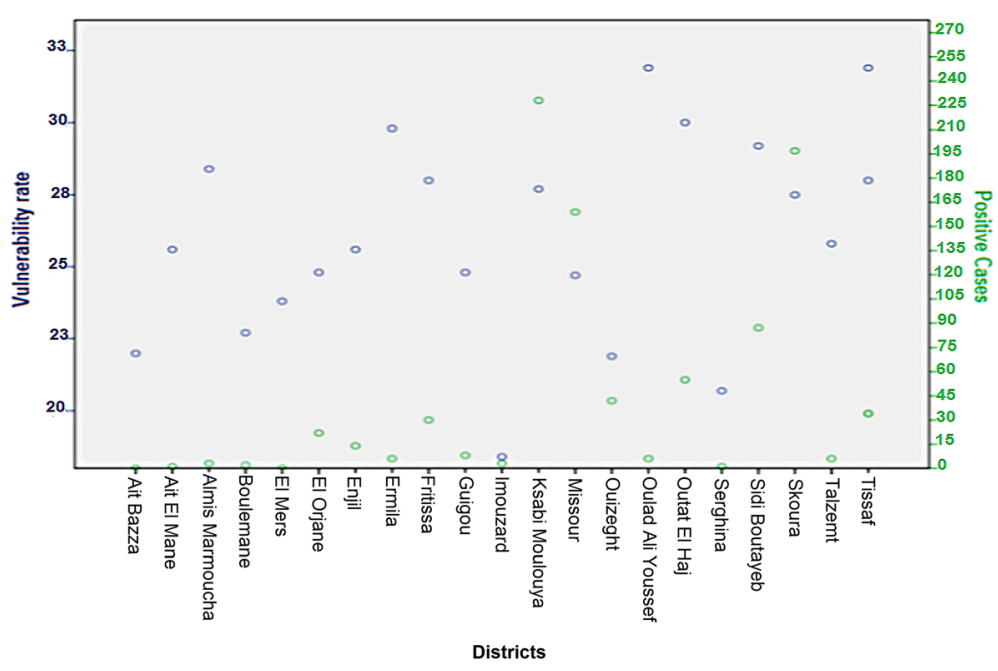

Fig. 6 Plot of distribution of leishmaniasis according to vulnerability rate in Boulemane Province 


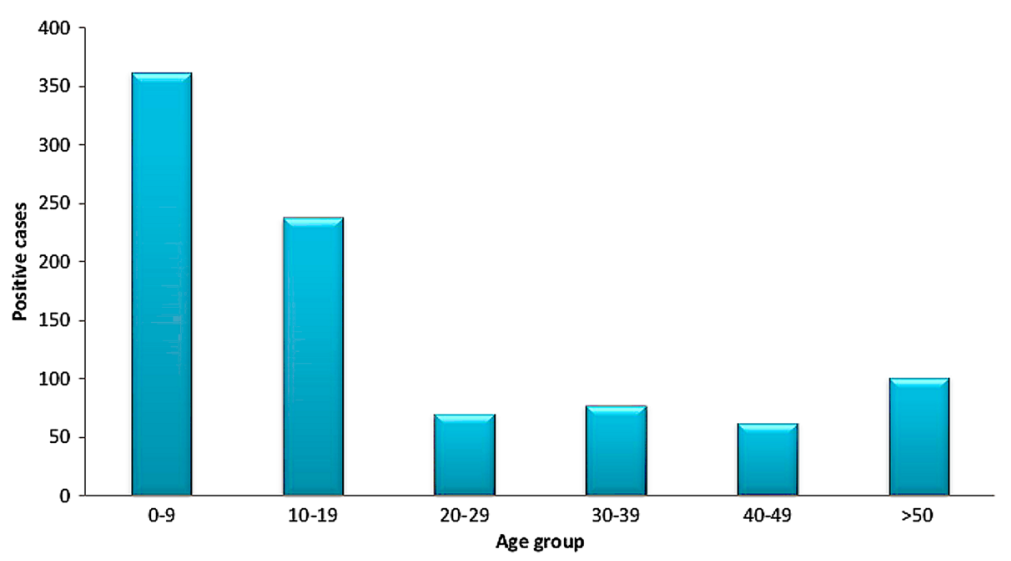

Fig. 7 Distribution of CL cases according to age in Boulemane Province (2000-2015)

perniciosus and P.longicuspis (18.7 and $11.2 \%$ respectively) [16]. The temporal evolution of CL cases due to L. tropica did not decrease over the years in Skoura district despite actions of control implemented in 2012, according to the delegation of health in Boulemane Province (eradication of sandflies and the early management of cases). In Morocco, the transmission cycle of L. tropica is still not well elucidated since it was isolated from dogs in Azilal and Essaouira provinces $[17,18]$. Therefore, control measures should consider the zoonotic transmission cycle of this species. The spatial distribution of leishmaniasis due to L. tropica has extended into Skoura. This could be due to the population movement from neighboring foci such as Sefrou Province and Taza $[19,20]$. This displacement of people is related to socio-economic factors namely the presence of a weekly market and olive crushing factories which constitute a meeting place for the local populace, including those from neighboring provinces. These meetings provide good conditions for transmission of the disease. In Missour district owing to semi-arid and Saharan areas, the two cases declared in 2015 were identified as L. tropica on the Saharan side after the elimination of $L$. major following the successful implementation of rodent control strategies. The presence of $L$. tropica could be due to the presence of its vector $P$. sergenti at lower densities and dominated previously by $P$. papatasi in this microclimate. This same result was found in Errachidia Province where the same action of control was implemented against rodents [21]. In 2015, an epidemic of CL was declared in Fritissa District (previously an unaffected area) belonging to several microclimate areas (semi-arid, arid and Saharan). In the context of public health surveillance, we have identified L. tropica in the three localities on the semi-arid side of this district. These localities are characterized by unfavorable conditions of hygiene which promote the presence of reservoir hosts and vectors and thus increase the risk of CL transmission.

Leishmania major was identified in the Saharan area in three affected districts in 2015, namely Ksabi Moulouya, Ouizeght and Sidi Boutayeb. These districts are situated at an altitude of 400 to $600 \mathrm{~m}$ where Phlebotomus papatasi predominates [5]. According to

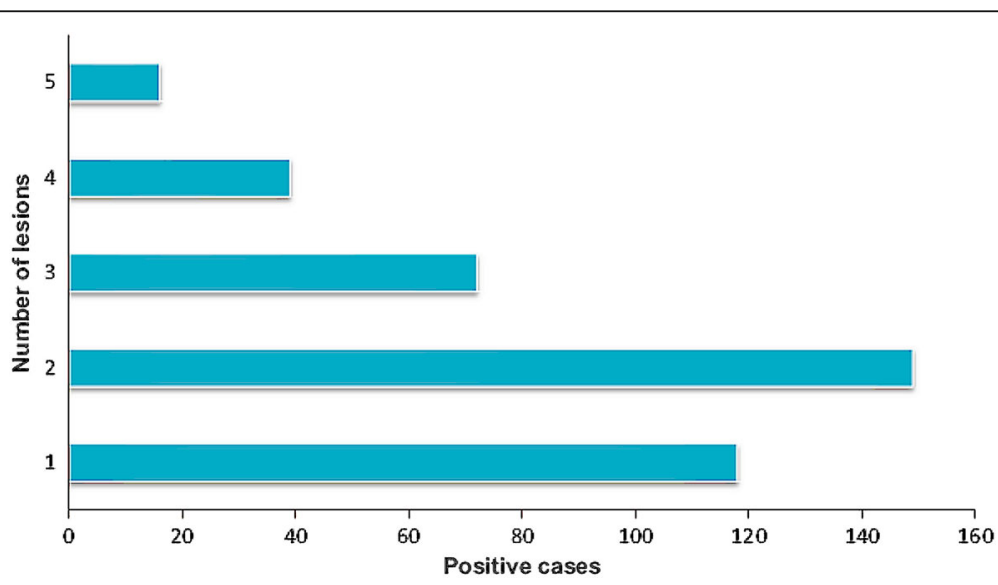

Fig. 8 Distribution of $C L$ cases according to number of lesions in Boulemane Province (2000-2015) 


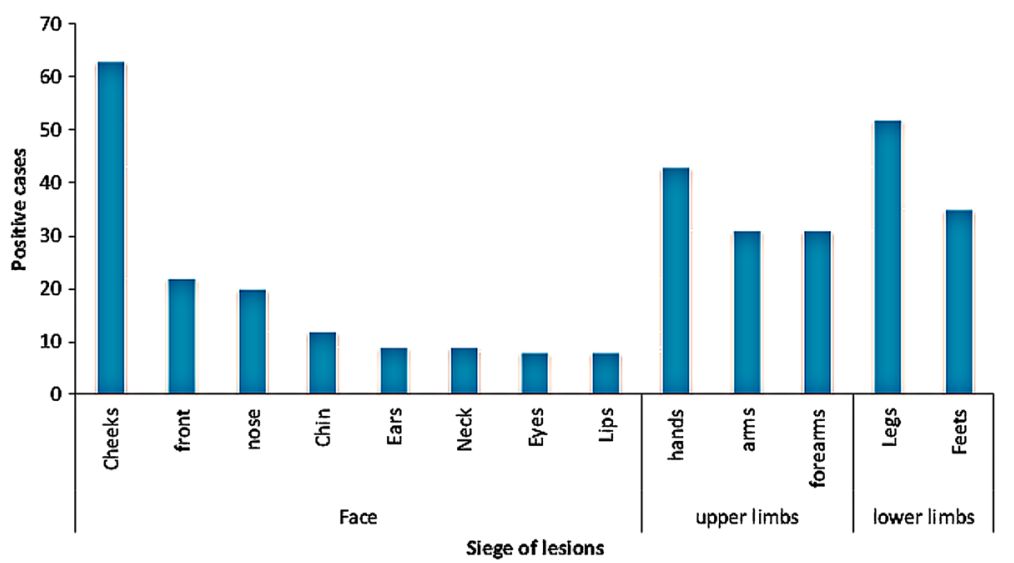

Fig. 9 Distribution of CL cases according to siege of lesions in Boulemane Province (2000-2015)

other studies, L. major is in circulation in Saharan areas $[14,22,23]$. The presence of $L$. major in all these districts could be explained by the geographical features of these districts characterized by the presence of River Moulouya, sandy soil and desert plants that constitute suitable environmental conditions for the spread of the disease since it facilitates the construction of rodent burrows; rodents being an important reservoir host [24]. Another factor which could increase the risk of leishmaniasis in Ksabi Moulouya District is the presence of a stone-pit (25,000 ha) which is an artificial environment that facilitates the breeding of sandflies. The temporal evolution of CL due to L. major in this province revealed fluctuations in cases over the years with an epidemic cycle of 4 to 5 years. This could be due to the application and looseness of measures of control focused mainly on rodents.

Cases of leishmaniasis due to L. major and L.tropica are related to poverty $(P$-value $=0.04)($ Fig. 4$)$. Other studies also support the relationship between the increase risk of $\mathrm{CL}$ and the poverty $[25,26]$. Moreover, our results highlight that the distribution of leishmaniasis was not influenced by urbanization since CL affects both urban and rural areas. In relation tourban areas, 159 cases were recorded in Missour

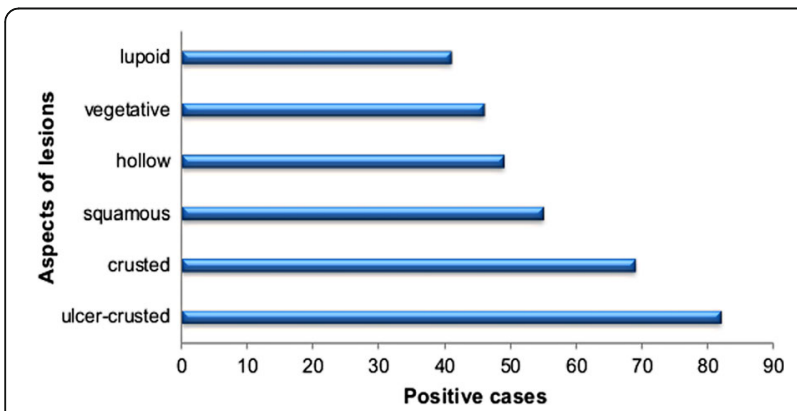

Fig. 10 Distribution of $C L$ cases according to aspect of lesions in Boulemane Province (2000-2015)
District which could be explained by its position as the administrative and commercial center of the province. Consequently, this district constitutes an area to which individuals from other neighboring affected foci, regularly travel to and meet. Also, this district is characterized by its high population density which promotes the installation of new settlements in the poor suburbs of this district, leading to inadequate sanitation and housing thus creating opportunities for the transmission of Leishmania. In rural areas, the increase of $\mathrm{CL}$ cases could be linked to human behavior through human-animal coexistence and the accumulation of livestock waste near habitations [27]. These factors represent favorable conditions for the spread of reservoir hosts and vectors $[28,29]$.

On the other hand, the OLSR analysis showed that the population density does not affect the incidence of the disease in this province (Fig. 5). Indeed, districts such as Enjil and Ermila with high population densities recorded a small number of cases (six and 14 cases, respectively) from 2000 to 2015. These districts are far from the leishmaniasis foci and the distance between their localities is wide which explains the stability of the population and therefore the low possibility of transmission.

During the study period two districts (Ait Bazza and El Mers) were not affected by the disease, but since these districts belong to the same biotope of other CL foci in this province such as Skoura District, the possibility of transmission still exists, should other factors (especially human behavior) allow it.

According to the clinical study of $\mathrm{CL}$ in Boulemane Province, the distribution of CL by age showed that all age groups were affected by the disease with the dominance of children from 0 to 9 years. This dominance could be explained by the relative immaturity of the cellular immunity of children and consequently the inability to fight the Leishmania infection [30]. Also, this could be due to the habits of children who often play near breeding sites [31]. 
Table 2 Results of molecular study of CL from the most affected district in Boulemane Province in 2015

\begin{tabular}{|c|c|c|c|c|c|c|c|}
\hline Province & District & Locality & Bioclimatic area & Urban/Rural & Result of ITS1 & Result of RFLP & Number of slides \\
\hline Boulemane & Ksabi Moulouya & Akhachab & Saharan & Rural & Positive & L. major & 1 \\
\hline Boulemane & Ksabi Moulouya & Issararen & Saharan & Rural & Positive & L. major & 1 \\
\hline Boulemane & Sidi Boutayeb & Bsabis & Saharan & Urban & Positive & L. major & 1 \\
\hline Boulemane & Ouizeght & Brija & Saharan & Rural & Positive & L. major & 2 \\
\hline Boulemane & Missour & Hay el qods & Saharan & Urban & Positive & L. tropica & 1 \\
\hline Boulemane & Missour & Pam & Saharan & Urban & Positive & L. tropica & 1 \\
\hline Boulemane & Fritissa & Oulad rzagh & Semi-arid & Rural & Positive & L. tropica & 8 \\
\hline Boulemane & Fritissa & oulad gharsalh & Semi-arid & Rural & Positive & L. tropica & 6 \\
\hline Boulemane & Fritissa & Oulad lahcen & Semi-arid & Rural & Positive & L. tropica & 1 \\
\hline Boulemane & Skoura & Bouassem & Semi-arid & Rural & Positive & L. tropica & 2 \\
\hline Boulemane & Skoura & Taghrout & Semi-arid & Rural & Positive & L. tropica & 2 \\
\hline Boulemane & Skoura & Skoura & Semi-arid & Rural & Positive & L. tropica & 2 \\
\hline
\end{tabular}

Concerning the clinical characterization, the results obtained were comparable to previous studies $[15,18]$. We observed the dominance of multiple lesions on the face and upper limbs. The multiplicity of lesions and their location on the limbs represents the classical form of CL due to L.major $[1,18]$. When a sandfly is disturbed during its blood meal, it can take its meal at multiple sites on the same host which could explain the multiplicity of lesions. This behavior is observed mainly in P.papatasi [32]. In this province, a diversity of clinical signs was observed generally indicative of CL due to $L$. major, namely ulcercrusted and vegetative lesions $[15,18]$. Lupoid lesions are also observed in this province which is a characteristic of CL due to L.tropica [33].

\section{Conclusions}

It appears that the increase of transmission of $\mathrm{CL}$ in Boulemane Province is related to several environmental factors such as poverty and population movement. The strength of this molecular epidemiological study lies in the molecular identification of the circulating species at each microclimate which can guide the control and

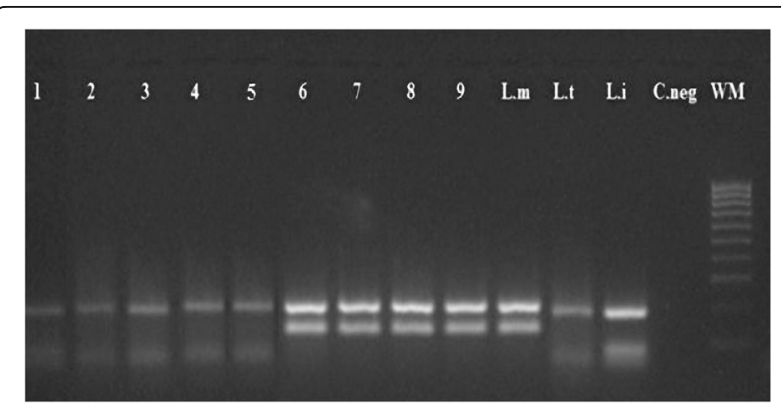

Fig. 11 Application of RFLP analysis of the ITS1-PCR analysis on positive amastigotes slides from Boulemane province. Lanes 1-9: samples from slides. Abbreviations; Lt, L. tropica; Li, L. infantum; Lm, L. major; C.neg, negative control; WM, weight maker $100 \mathrm{bp}$ surveillance strategies implemented to manage $\mathrm{CL}$ in this province.

\section{Abbreviations}

CL: Cutaneous leishmaniasis; NRLL: National Reference Laboratory of Leishmaniasis; OLSR: Ordinary least squares regression

\section{Acknowledgements}

The authors would like to thank the staff of Ambulatory services of provincial infrastructures of Boulemane Province which gave data concerning samples and the study area.

\section{Funding}

Not applicable.

\section{Availability of data and materials}

The data used in this study are included within the article.

\section{Authors' contributions}

HA conceived the study, carried out all the technical experiments and drafted the paper, EMM performed the statistical analysis, HM, BK, and AF participated in the review of the manuscript, $\mathrm{HM}$, participated in the conducting of the molecular study, $\mathrm{DH}$ collected and provided data of the study area, HK, FH revised and approved the paper and SF conceived and directed the study. All authors read and approved the final manuscript.

\section{Competing interests}

The authors declare that they have no competing interests.

\section{Consent for publication}

Not applicable.

\section{Ethics approval and consent to participate}

As part of National Program for the control of Leishmaniasis, quality control of microscopic diagnosis of cutaneous and visceral leishmaniasis was implemented since 2000, by our laboratory: the National Reference Laboratory of Leishmaniasis (NRLL) of the National Institute of Hygiene of Morocco. Thus, the public health laboratories send to our laboratory, smear and bone marrow for conformation and control. The process of sampling of patients referred to the method indicated in the guide of activities entitled "Control of leishmaniasis = LUTTE CONTRE LES LEISHMANIOSES" elaborated in 2010 by the Ministry of Health, Directorial of Epidemiology and Disease Control and the National Institute of Hygiene of Morocco. The system of external quality control of laboratories established by the $N R L L$, aims to improve the performance of laboratories. Also, the NRLL collected strains of Leishmania at a provincial level during the studies of foci, or from patients who consult the National Institute of Hygiene of Morocco for diagnosis and culture. Since 2010, molecular identification of Leishmania species circulating in Morocco was performed in this laboratory. In addition, the NRLL provides, at 
the provincial level, training services personnel of parasitic diseases, supervision, installation and endowment reagents and fungible materials for public health leishmaniasis laboratories. These missions are designed to improve the care of patients and to optimize activities against this parasite.

Consent to participate: The data analyzed in this paper do not contain any personal information relating to individual participants (name, image, videos, address ...). Consequently, we have the right to diagnose and identify the samples received in the National Laboratory of Leishmaniasis in order to guide the strategy of control.

\section{Author details}

${ }^{1}$ National Reference Laboratory of Leishmaniasis, National Institute of Hygiene, Rabat, Morocco. ${ }^{2}$ Laboratory of Microbial Biotechnology, Sciences and Techniques Faculty, Sidi Mohammed Ben Abdellah University, Fez, Morocco. ${ }^{3}$ Laboratory of Zoology and General Biology, Faculty of Sciences, Mohammed V University, Rabat, Morocco. ${ }^{4}$ Institute of Nursing Professions and Health Techniques, Casablanca, Morocco. ${ }^{5}$ Delegation of Ministry of health, Provincial Laboratory of Parasitic Diseases, Boulemane, Morocco. ${ }^{6}$ Faculty of Sciences and Techniques, Sultan Moulay Slimane University, Beni Mellal, Morocco.

\section{Received: 1 October 2016 Accepted: 10 February 2017} Published online: 22 February 2017

\section{References}

1. WHO Control of the leishmaniasis. Report of a WHO expert committee. Geneva: WHO Technical Report Series; 2010. p. 793.

2. Moroccan Ministry of Health. Etat d'avancement des programmes de lutte contre les maladies parasitaires. Rabat: Direction épidémiologique et de lutte contre les maladies; 2015.

3. Chaves LF, Pascual M. Climate cycles and forecasts of cutaneous leishmaniasis, a non stationary vector-borne disease. PLoS Med. 2006;3:1320-8.

4. Ministère chargé de l'aménagement du territoire, de l'eau, et de l'environnement, programme des nations unies pour l'environnement: convention de la diversité biologique au Maroc;1990.https://www.cbd.int/ doc/world/ma/ma-nr-01-p1-fr.pdf. Accessed 04 Dec 2016.

5. Rioux JA, Rispail P, Lanotte G, Lepart J. Relations phlébotomes-bioclimats en écologie des leishmanioses Corollaires épidémiologiques, l'exemple du Maroc. Bull Soc Bot Fr. 1984:131:549-57.

6. Ministère de l'intérieur, Royaume du Maroc, Wilaya de la région de FèsBoulemane, centre régional d'investissement, Monographie de la région Fès-Boulemane Novembre, 2013.http://www.crifes.ma/docs/ 122082014002127.pdf. Accessed 09 Dec 2016.

7. Ministère de l'habitat et de l'urbanisme, direction de l'aménagement du territoire: Etude du schéma régional d'aménagement du territoire de la région de Fès Boulemane. Uram Intl. 2013.http://www.srat-rfb.info/documents/MILIEU\%20 PHYSIQUE\%20RESSOURCES\%20ET\%20ENVIRONNEMENT.pdf?PHPSESSID= 51266d699fc656719e963a5fe2bab51a. Accessed 04 Dec 2016.

8. Haut Commissariat au Plan (HCP). Recensement général de la population et de l'habitat. 2014. http://rgph2014.hcp.ma/downloads/Publications-RGPH2014_t18649.html. Accessed 04 Dec 2016.

9. Haut Commissariat au Plan (HCP). Carte de la pauvreté au Maroc. 2007. file:/// C:/Users/hp/Downloads/Carte\%20de\%20la\%20pauvret\%C3\%A9\%202007. \%20Rapport.pdf. Accessed 04 Dec 2016.

10. Agence du Bassin Hydraulique de Sebou (ABHS). Etude du schéma directeur d'assainissement rural de la région de Fès-Boulemane. 2011. http://www.sratrfb.info/documents/MILIEU\%20PHYSIQUE\%20RESSOURCES\%20ET\%20ENVIRON NEMENT.pdf?PHPSESSID=51266d699fc656719e963a5fe2bab51a. Accessed 04 Dec 2016.

11. Moroccan Ministry of Health. Direction épidémiologique de lutte contre les maladies. Lutte contre les Leishmanioses : Guide des Activités. 1997. http:// sehati.gov.ma/uploads/Guide_des_activites_de_lutte_contre_les_leishma nioses.pdf. Accessed 17 Jan 2017.

12. Mahdy MAK, Al-Mekhlafi MH, Al-Mekhlafi MA, Lim YAL, Bin Shuaib NMO, Azazy AA, et al. Molecular characterization of Leishmania species isolated from cutaneous leishmaniasis in Yemen. PLoS One. 2010;5:1-4.

13. Schönian G, Nasereddin A, Dinse N, Schweynoch C, Schallig HD, Presber W, et al. PCR diagnosis and characterization of Leishmania in local and imported clinical samples. Diagn Microbiol Infect Dis. 2003:47:349-58.
14. Lahouari B, Kahime K, Houti L, Blakey T, Ebi K, Zhang P, et al. Linking climate to incidence of zoonotic cutaneous leishmaniasis (L. major) in pre-Saharan North Africa. Int J Environ Res Public Health. 2013;10:3172-91.

15. Rhajaoui M, Abdelmajeed N, Fellah H, Azmi K, Amrir F, Al-jawabreh A, et al. New clinico epidemiologic profile of cutaneous leishmaniasis, Morocco. Emerg Infect Dis. 2007:9:1358-60.

16. Faraj C, Adlaoui E, Ouahabi S, El Kohli M, El Rhazi M, Lakraa L, et al. Distribution and bionomic of sand flies in five ecologically different cutaneous leishmaniasis foci in Morocco. ISRN Epidemiol. 2012;1:8.

17. Dereure J, Rioux JA, Gallego M, Perieres J, Pratlong F, Mahjour J, et al. Leishmania tropica in Morocco: infection in dogs. Trans R Soc Trop Med Hyg. 1991;85:595.

18. Chaara D, Haouas N, Dedet JP, Babba H, Pratlong F. Leishmaniases in Maghreb: an endemic neglected disease. Act Trop. 2014;132:80-93.

19. Hmamouch A, Amarir F, Fellah H, Karzaz M, Bekhti K, Rhajaoui M, et al. Coexistence of Leishmania tropica and Leishmania infantum in Sefrou province, Morocco. Act Trop. 2014;130:94-9.

20. Guessous-Idrissi N, Chiheb S, Hamdani A, Riyad M, Bichichi M, Hamdani S, et al. Cutaneous leishmaniasis: an emerging epidemic focus of Leishmania tropica in north Morocco. Trans Roy Soc Trop Med Hyg. 1997;91:660-3.

21. El Alem MM, Sebti F, Med L, Chichaoui S, El Bachir A, Habbari K, et al. Geographical distribution and new situation of Leishmania species after the control of cutaneous leishmaniasis foci in Errachidia Province, Morocco, in 2014. Bio Med Res Int. 2016. doi:10.1155/2016/8642373.

22. Bennis I, De Brouwere V, Ameur B, El idrissi laamrani A, Chichaoui S, Sahibi $\mathrm{H}$, et al. Control of cutaneous leishmaniasis caused by Leishmania major in south-eastern Morocco. Trop Med Int Health. 2015;10:1297-305.

23. Dedet JP, Pratlong F, Cook GC, Zumla Al. Leishmaniasis. In: Manson's Tropical Diseases. 22nd ed. London: Saunders; 2009. p. 1341-65.

24. Ernest SKM, Brown JH, Parmenter RR. Rodents plants and precipitation: spatial and temporal dynamics of consumers and resources. Oikos. 2000;88:470-82.

25. Oryan A, Alidadi S, Akbari M. Risk factors associated with leishmaniasis. Trop Med Surg. 2014;2:e118

26. Alvar J, Yactayo S, Bern C. Leishmaniasis and poverty. Trends Parasitol. 2012; 22:552-7.

27. Nunes WDS, Sócrates RA, Cláudia MLC. Epidemiological profile of leishmaniasis at a reference service in the state of Alagoas, Brazil, from January 2000 to September 2008. Braz J Infect Dis. 2010;14(4):342-5.

28. Reithinger R, Mohsen M, Leslie T. Risk factors for anthroponotic cutaneous leishmaniasis at the household level in Kabul, Afghanistan. PLoS Negl Trop Dis. 2010:4:639.

29. Ghatee MA, Sharifi I, Haghdoost AA, Kanannejad Z, Taabody Z, et al. Spatial correlations of population and ecological factors with distribution of visceral leishmaniasis cases in southwestern Iran. J Vector Borne Dis. 2013;50(3):179-87.

30. Arroub H, Alaoui A, Lemrani M, Habbari K. Cutaneous leishmaniasis in foum jamâa (Azilal, Morocco): micro-environmental and socio-economical risk factors. J Agric Soc Sci. 2012;8:10-6.

31. Amarir F, Sebti F, Fellah H, Pratlong F, Dedet JP, et al. Epidemiological characteristics of a new focus of cutaneous leishmaniasis caused by Leishmania tropica in Settat, Morocco. Act Trop. 2015;150:116-21.

32. Chiheb S, Slawi W, Mouttaqui T, Riyad M, Benchikhi H. Les leishmanioses cutanées à Leishmania major et à Leishmania tropica au Maroc: aspects épidémio-cliniques comparatifs de 268 cas. Pan Afr Med J. 2014;19:1-9.

33. Chiheb S, Hamdani A, Riyad M, Bichichi M, Hamdani S, et al. Leishmania tropica cutaneous leishmaniasis in an emerging focus in North Morocco: new clinical forms. Ann Dermatol Venereol. 1999;126(5):419-22.

\section{Submit your next manuscript to BioMed Central} and we will help you at every step:

- We accept pre-submission inquiries

- Our selector tool helps you to find the most relevant journal

- We provide round the clock customer support

- Convenient online submission

- Thorough peer review

- Inclusion in PubMed and all major indexing services

- Maximum visibility for your research

Submit your manuscript at www.biomedcentral.com/submit 